\title{
EFEITOS LOCAIS DOS DETERMINANTES DO CRESCIMENTO DA AGROINDÚSTRIA NO BRASIL ${ }^{\circ}$
}

\author{
LOCAL EFFECTS OF AGROINDUSTRY GROWTH \\ DETERMINANTS IN BRAZIL
}

\author{
Jackelline Favro* \\ Alexandre Florindo Alves ${ }^{* *}$
}

enviado: 29 diciembre 2019 - aceptado: 15 mayo 2020

\begin{abstract}
Resumo
Este estudo tem por objetivo analisar o crescimento da agroindústria no Brasil no período de 2006 a 2016. Para tanto utilizou-se a Análise Exploratória de Dados Espaciais (AEDE) e a Regressão Ponderada Geograficamente (RPG). A AEDE indicou a existência de autocorrelação espacial positiva no crescimento dos estabelecimentos da agroindústria, já os resultados da RPG, que estima os efeitos locais do modelo em questão, evidenciaram o efeito local das variáveis PIB per capita, quociente locacional da agropecuária, valor adicionado da agropecuária, área da microrregião e percentual de funcionários com nível de ensino médio nas microrregiões das regiões Norte e Nordeste do país, regiões que apresentaram as maiores taxas de crescimento no período e contribuíram significativamente com o crescimento da agroindústria.
\end{abstract}

Palavras-chave: RPG, agroindústria, localização.

Classificação JEL: R12, R3, L660.

Favro, J., \&, Alvez, A. F. (2021). Efeitos locais dos determinantes do crescimento da agroindústria no Brasil. Estudios económicos, 38(76),223-257.

* Programa de Pós-Graduação em Ciências Econômicas da Universidade Estadual de Maringá, Brasil. E-mail: jacke.favro@gmail.com ORCID: https://orcid.org/0000-0002-4027-5821

** Programa de Pós-Graduação em Ciências Econômicas da Universidade Estadual de Maringá, Brasil E-mail: afalves@uem.br

ORCID: https://orcid.org/0000-0003-4640-6543 


\begin{abstract}
This study aims to analyze the growth of agroindustry in Brazil in the period from 2006 to 2016. For this purpose, the Exploratory Spatial Data Analysis (ESDA) and the Geographically Weighted Regression (GWR) were used. The ESDA indicated the existence of positive spatial autocorrelation in the growth of agribusiness establishments, while the results of the RPG, which estimates the local effects of the model in question, showed the local effect of the variables GDP per capita, locational quotient of agriculture, livestock value added. agriculture, microregion area and percentage of employees with high school level in the microregions of the North and Northeast regions of the country, regions that presented the highest growth rates in the period and contributed significantly to the growth of the agroindustry.
\end{abstract}

Keywords: GWR, agroindustry, location.

JEL Codes: R12, R3, L660. 


\section{INTRODUÇÃO}

Em uma sociedade cada vez mais industrializada, globalizada e urbanizada, o agronegócio e os sistemas agroalimentares, em geral, vêm se transformando rapidamente. Nesse contexto, em virtude do aumento da demanda por alimentos e demais produtos processados derivados da agropecuária, constata-se a importância da agroindústria ${ }^{1}$, segmento com potencial de contribuir para o crescimento econômico, principalmente em países em desenvolvimento, em virtude de se destacarem como grandes produtores e exportadores de produtos agroindustriais (Gálvez et al., 2017).

No Brasil, os segmentos que compõem a agroindústria passaram a se expandir mais fortemente a partir de 2007. No período de 2007 a 2015, ramos como preparação de couros e seus artefatos, fabricação de produtos alimentícios, fabricação de bebidas, de produtos têxteis e vestuário apresentaram trajetória de crescimento, impulsionados, dentre outros fatores, pelo aumento do consumo interno e crescimento da demanda mundial (Monteiro Neto \& Silva, 2018).

Segundo informações do Ministério do Trabalho e Emprego (2018), em 2006 o Brasil possuía 79.684 estabelecimentos da agroindústria (sentido amplo), enquanto que no ano de 2016 esse número passou para 93395 estabelecimentos, representando um aumento de $17 \%$ no período.

Nesse sentido, faz-se necessário entender a distribuição espacial dos estabelecimentos da agroindústria, visando-se compreender os elementos que podem influenciar seu dinamismo. Sendo assim, este estudo tem por objetivo analisar o crescimento da agroindústria no Brasil no período de 2006 a 2016. Especificamente se pretende explorar os determinantes da localização para o segmento da agroindústria; testar a hipótese de que, em virtude das características regionais peculiares observadas no Brasil (qualidade da mão de obra, infraestrutura adequada, condições econômicas, acesso à matéria - prima), a quantidade de estabelecimentos da agroindústria cresceu em intensidade diferente nas microrregiões brasileiras; e verificar

1 Compreende-se como agroindústria toda atividade de beneficiamento e/ou transformação de matérias - primas derivadas de produtos agrícolas, pecuários, pesqueiros, aquícolas, extrativistas e florestais, compreendendo desde os processos mais simples, como secagem, classificação, limpeza e embalagem, até os mais complexos que abrangem operações físicas, químicas ou biológicas como, por exemplo, a extração de óleos, a caramelização e a fermentação, incluindo também o artesanato no meio rural (MDA, 2007). 
o nível de influência que cada fator tem na configuração dos determinantes da agroindústria em cada microrregião do país.

Para tanto, utilizam-se como ferramentas metodológicas a Análise Exploratória de Dados Espaciais (AEDE) e o modelo que considera a heterogeneidade espacial extrema, o modelo de Regressão Ponderada Geograficamente (RPG).

A utilização de modelos espaciais nesse tipo de análise se justifica por meio de três fatores fundamentais: primeiro, a estrutura tradicional que não controla as variáveis espaciais não é capaz de capturar a presença de transbordamentos espaciais; segundo, a distribuição espacial das empresas não é, de forma alguma, homogênea e, portanto, não se podem ignorar as possíveis influências do contexto espacial sobre as decisões de localização; e, em terceiro, não avaliar os efeitos espaciais pode implicar desconsiderar nas análises as economias de aglomeração que tendem a surgir nas atividades econômicas (Li \& Zhu, 2017).

O presente artigo está organizado da seguinte forma: além desta introdução, consta de mais seis seções. Na segunda seção, apresenta-se o panorama locacional da agroindústria no Brasil. Na sequência, seção três, apresenta-se uma revisão bibliográfica acerca dos determinantes da localização industrial; na seção quatro, descrevem-se a metodologia, modelo proposto, fontes e tratamentos de dados. A quinta seção expõe os resultados e as discussões do trabalho, e a última seção trata das considerações finais.

\section{PANORAMA LOCACIONAL DA AGROINDÚSTRIA NO BRASIL}

A agroindústria brasileira vem se desenvolvendo e se destacando ao longo dos últimos anos. Em termos econômicos, sua importância pode ser verificada na participação no agronegócio, na indústria de transformação e nas exportações. De acordo com os dados do Cepea (2018), no período de 1996 a 2016, esse segmento representou, em média, 30\% do PIB do agronegócio brasileiro.

Já em relação ao Valor da Transformação Industrial da Indústria de Transformação, de 2010 a 2017, a participação da Agroindústria passou de 207 bilhões (ou 28,5\% VTI da Indústria de Transformação) para 357 bilhões (35\% VTI da Indústria de Transformação) (IBGE, 2019). Esse incremento da participação está relacionado, dentre outros fatores, ao aumento das demandas interna e externa e às mudanças nos padrões de consumo da população. Esses elementos podem ser 
considerados motores da expansão da agroindústria, em termos absolutos, e da manutenção da sua participação na produção industrial (Santos, 2014).

A expansão da produção agroindustrial se traduziu em elevada disponibilidade de alimentos, fibras e energia, garantindo o abastecimento interno e ainda um crescente volume de exportação (Cepea, 2018). De acordo com os dados do Ministério da Economia, Indústria, Comércio Exterior e Serviços (2019), as exportações de produtos agroindustriais (em toneladas) apresentaram, no período compreendido entre 1997 a 2017, taxa de crescimento anual de 5.78\%. Esse fato evidencia a importância deste segmento na geração de divisas para o país.

Apesar de se constatar o crescimento da agroindústria ao longo do período, é relevante analisar se esse fato também se verifica quando se observam os dados referentes aos estados e regiões. Esse fator é importante, pois por meio de uma análise desagregada em nível regional, é possível observar, em termos espaciais, a localização da agroindústria e seu grau de importância entre as regiões.

Na Tabela 1 são apresentados os dados referentes ao número de estabelecimentos da agroindústria por estados e regiões. Constata-se que as regiões Sul e Sudeste concentraram o maior número de estabelecimentos da agroindústria, tanto em 2006 quanto em 2016, apresentando uma participação de 72\% e 70\%, respectivamente. De acordo com Santos (2013), a justificativa para a grande concentração da agroindústria nessas regiões, dentre outros fatores, consiste no fato de elas disporem de grande oferta de matéria-prima, estarem próximas do mercado consumidor e possuírem maior organização produtiva.

As regiões Norte, Nordeste e Centro-Oeste do país não seguem o mesmo perfil de atração da agroindústria no nível das regiões Sul e Sudeste, porém pode-se verificar que estas regiões, ao longo do período em análise, apresentaram expressivas taxas de crescimento da planta agroindustrial.

Dentre os fatores que contribuíram para o crescimento da agroindústria nestas regiões, estão as combinações de alocação dos fatores de produção e incentivos dos governos estaduais que possibilitaram a instalação de agroindústrias mesmo em regiões de baixa oferta de matérias - primas. No Norte e Nordeste, o alto peso desse segmento se deve à questão estrutural, além do fator importante que é a base no consumo regional e a mão de obra relativamente barata, somado a outros custos menores, mais a existência de um grande mercado consumidor que viabiliza a produção da agroindústria, mesmo sem uma grande produção agropecuária. No Centro-Oeste, a importância relativa da agroindústria está ligada à grande produ- 
ção agropecuária, com atração de indústrias de médio e grande porte, além de a região apresentar menor participação relativa de outros segmentos da indústria de transformação (Santos, 2013).

Sendo assim, observa-se que diversos indicadores podem contribuir para o desenvolvimento da agroindústria, sendo a oferta de matéria-prima um dos mais importantes. Para Santos (2014), a oferta de matéria-prima potencializa uma região, em relação a outras, no estabelecimento de agroindústrias.

Tabela 1. Total de estabelecimentos da agroindústria por estados nos anos 2006 e 2016

\begin{tabular}{|c|c|c|c|c|c|}
\hline Estados & 2006 & $\%$ & 2016 & $\%$ & $\Delta 06 / 16$ \\
\hline Rondônia & 1054 & 1.32 & 1101 & 1.18 & 4.46 \\
\hline Acre & 215 & 0.27 & 262 & 0.28 & 21.86 \\
\hline Amazonas & 352 & 0.44 & 482 & 0.52 & 36.93 \\
\hline Roraima & 102 & 0.13 & 134 & 0.14 & 31.37 \\
\hline Pará & 1820 & 2.28 & 1881 & 2.01 & 3.35 \\
\hline Amapá & 83 & 0.10 & 153 & 0.16 & 84.34 \\
\hline Tocantins & 281 & 0.35 & 413 & 0.44 & 46.98 \\
\hline Região Norte & 3907 & 4.90 & 4426 & 4.74 & 13.28 \\
\hline Maranhão & 529 & 0.66 & 789 & 0.84 & 49.15 \\
\hline Piauí & 584 & 0.73 & 855 & 0.92 & 46.40 \\
\hline Ceará & 2346 & 2.94 & 2963 & 3.17 & 26.30 \\
\hline Rio Grande do Norte & 933 & 1.17 & 1418 & 1.52 & 51.98 \\
\hline Paraíba & 1034 & 1.30 & 1381 & 1.48 & 33.56 \\
\hline Pernambuco & 2516 & 3.16 & 3228 & 3.46 & 28.30 \\
\hline Alagoas & 501 & 0.63 & 724 & 0.78 & 44.51 \\
\hline
\end{tabular}


EFEITOS LOCAIS DOS DETERMINANTES DO CRESCIMENTO DA AGROINDÚSTRIA NO BRASIL

\begin{tabular}{|c|c|c|c|c|c|}
\hline Sergipe & 484 & 0.61 & 605 & 0.65 & 25.00 \\
\hline Bahia & 2712 & 3.40 & 3708 & 3.97 & 36.73 \\
\hline Região Nordeste & 11639 & 14.61 & 15671 & 16.78 & 34.64 \\
\hline Minas Gerais & 10822 & 13.58 & 13064 & 13.99 & 20.72 \\
\hline Espírito Santo & 1272 & 1.60 & 1792 & 1.92 & 40.88 \\
\hline Rio de Janeiro & 3005 & 3.77 & 3495 & 3.74 & 16.31 \\
\hline São Paulo & 16157 & 20.28 & 17177 & 18.39 & 6.31 \\
\hline Região Sudeste & 31256 & 39.22 & 35528 & 38.04 & 13.67 \\
\hline Paraná & 8401 & 10.54 & 9653 & 10.34 & 14.90 \\
\hline Santa Catarina & 7476 & 9.38 & 9020 & 9.66 & 20.65 \\
\hline Rio Grande do Sul & 10315 & 12.94 & 10969 & 11.74 & 6.34 \\
\hline Região Sul & 26192 & 32.87 & 29642 & 31.74 & 13.17 \\
\hline Mato Grosso do Sul & 910 & 1.14 & 1199 & 1.28 & 31.76 \\
\hline Mato Grosso & 2334 & 2.93 & 2453 & 2.63 & 5.10 \\
\hline Goiás & 2951 & 3.70 & 3666 & 3.93 & 24.23 \\
\hline Distrito Federal & 495 & 0.62 & 810 & 0.87 & 63.64 \\
\hline Região Centro-Oeste & 6690 & 8.40 & 8128 & 8.70 & 21.49 \\
\hline Total no Brasil & 79684 & 100 & 93395 & 100 & 17.21 \\
\hline
\end{tabular}

Fonte: elaboração própria a partir de dados da RAIS (2018).

Após a análise do panorama locacional da agroindústria, é possível ter uma visão geral da distribuição desse segmento na economia brasileira. Estes dados apontam para a necessidade de se aprofundarem os estudos sobre os aspectos locacionais que contribuem para o desenvolvimento da agroindústria, principalmente em regiões que apresentaram crescimento elevado ao longo do período. 


\section{REFERENCIAL EMPÍRICO}

Ao longo dos últimos anos, diversos estudos foram realizados com os objetivos de analisar a localização industrial e identificar os fatores locacionais que refletem as reais decisões de localização da planta industrial (Gotardo, 2016). Tais pesquisas utilizaram diferentes bases de dados e distintas metodologias. Em meio a esses estudos podem ser destacados os que enfatizam a localização da agroindústria, tais como Goetz (1997), Henderson \& Namara (1997), Davis \& Schluter (2005), Lambert \& Namara (2009), Polyzos et al. (2015), Barrantes et al. (2015), Wu (2017), Granco et al. (2018) e Takano \& Kikukawa (2018). O Quadro 1 foi construído com base nos trabalhos mencionados e permite ter uma visão resumida dos estudos realizados. Destarte, a apresentação desses estudos busca verificar as variáveis utilizadas na especificação dos modelos referentes aos determinantes da localização da indústria e do crescimento dos estabelecimentos industriais.

Os trabalhos analisados (Quadro 1) apresentam as variáveis relevantes para a análise da localização industrial e os principais estudos nessa área. O objetivo dessa análise é investigar, com maior acuidade, as principais variáveis utilizadas nas estimações empíricas, sendo que servirão como suporte ao modelo a ser construído neste estudo.

Apesar das diferenças nas abordagens mais recentes, observa-se certa homogeneidade nos fatores que são testados como determinantes locacionais da indústria, como impostos, mão de obra (tanto qualificação como custo da mão de obra), custos com transporte, urbanização, incentivos fiscais, infraestrutura, aglomeração, mercado consumidor, fonte de matéria-prima e fornecedores de insumos, que são alguns dos fatores que aparecem com frequência nesse tipo de análise (Gotardo, 2016).

\section{METODOLOGIA}

\section{III.1. Análise exploratória de dados espaciais (AEDE)}

A análise exploratória dos dados espaciais (AEDE) aborda os efeitos decorrentes da autocorrelação espacial que ocorre quando o valor de uma variável numa região $i$, por exemplo, está relacionada com o valor da mesma variável da região $j$ (Anselin, 1988). 


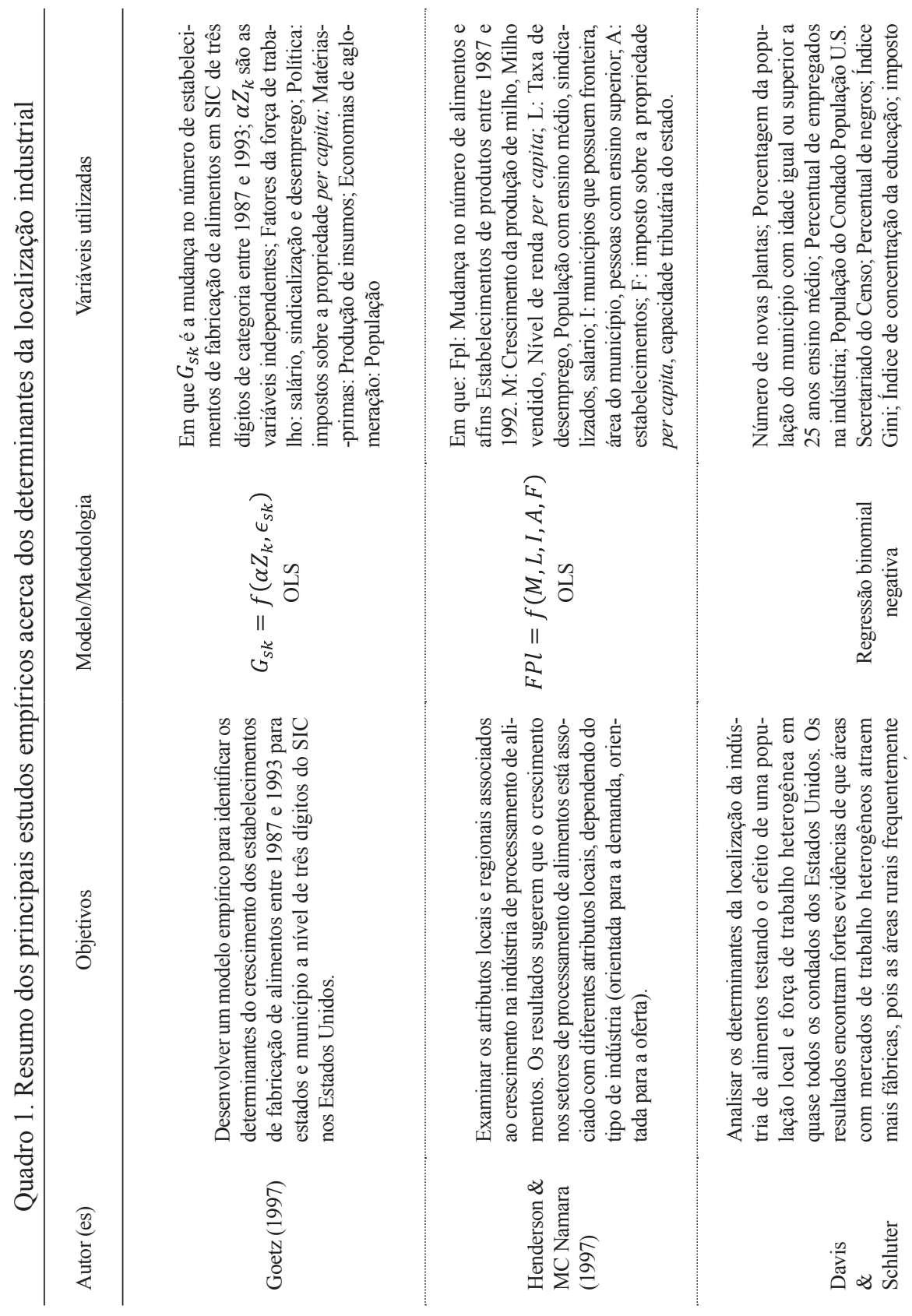




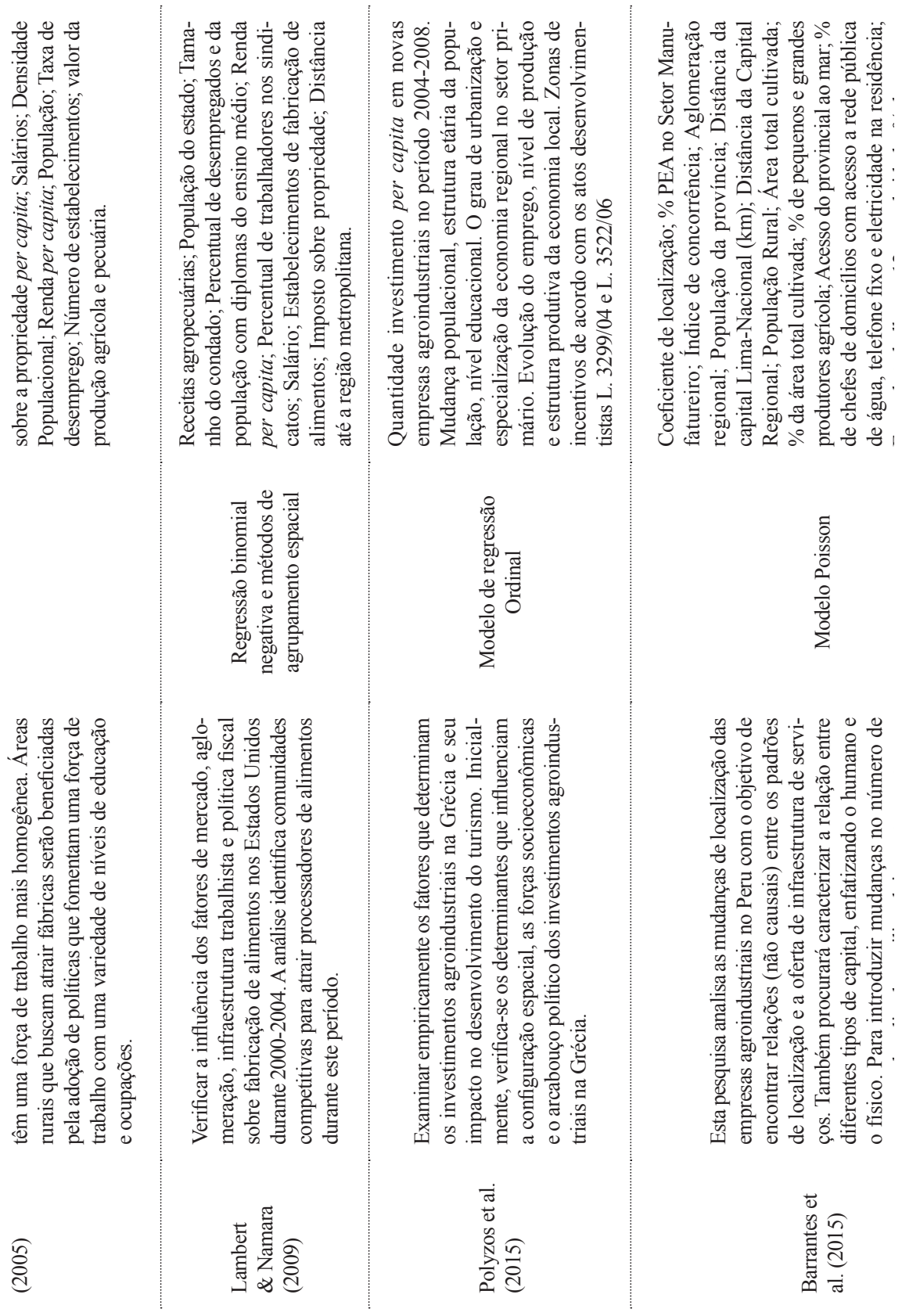




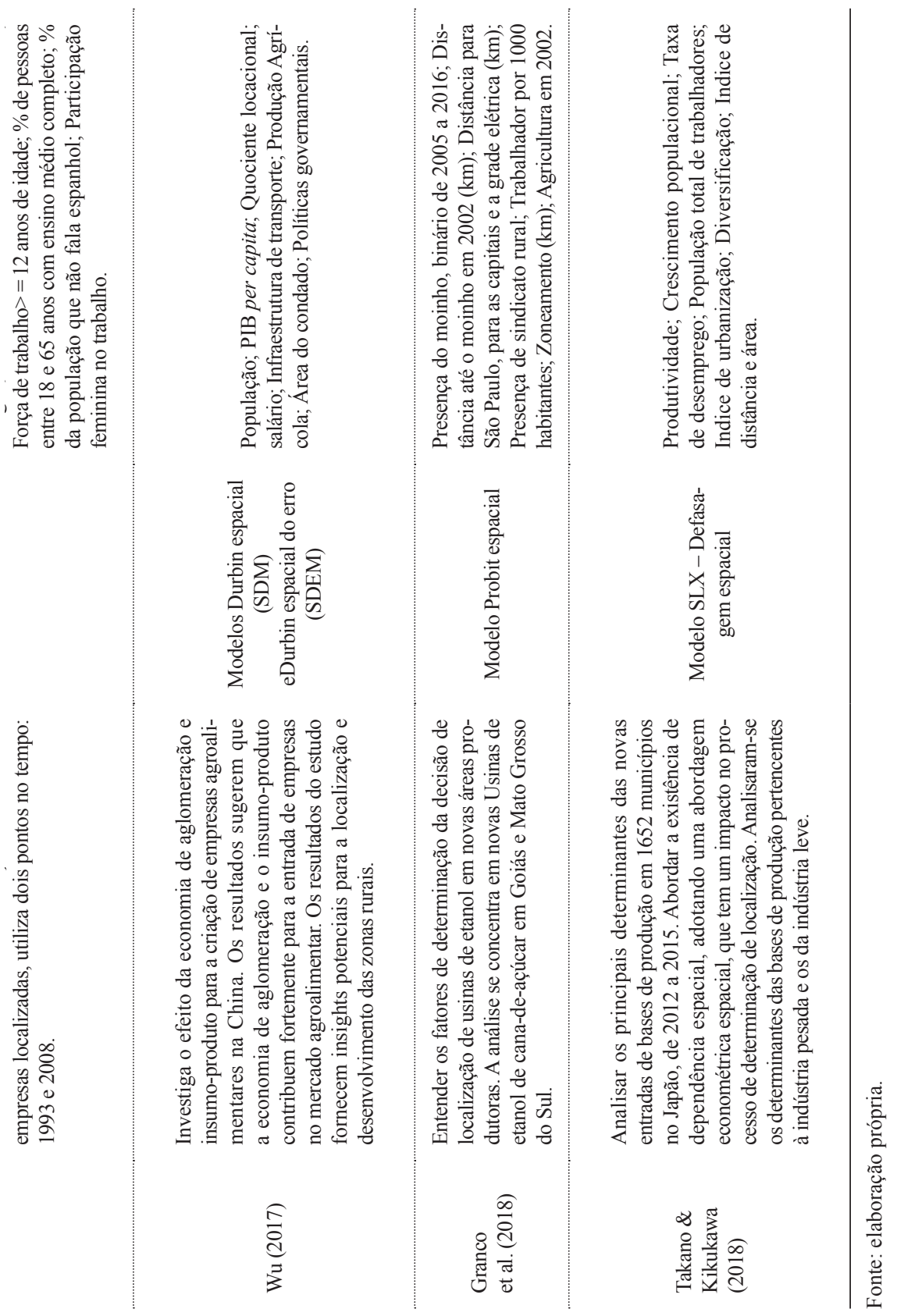


O primeiro passo no estudo da AEDE é testar a hipótese de que os dados espaciais sejam distribuídos aleatoriamente, ou seja, verificar se os valores de um atributo numa região não dependem dos valores deste atributo nas regiões vizinhas. Os dados espaciais podem ser definidos como sendo a observação de uma variável que se encontra associada a uma localização no espaço geográfico (Sabater et al., 2011).

A estatística $I$ de Moran consiste em um teste de diagnóstico global que mede o grau de associação linear entre um atributo $(y)$ em determinado local e a média ponderada do atributo nos locais vizinhos $(W y)$. Valores maiores (ou menores) do que o esperado $E(I)=\frac{1}{N-1}$ significam que há autocorrelação positiva (ou negativa).

O diagrama de dispersão de Moran é uma das maneiras de se interpretar a estatística $I$ de Moran. Ele permite visualizar a correlação linear entre $z$ e $W z$ por meio do gráfico de duas variáveis. O coeficiente $I$ de Moran é a inclinação da curva de regressão de $W z$ contra $z$ e esta inclinação indica o grau de ajustamento. O diagrama é dividido em quatro quadrantes, os quais correspondem a quatro padrões de associação local espacial entre as regiões e seus vizinhos. As regiões que se localizam no primeiro e terceiro quadrantes (AA (Alto-Alto) e BB (Baixo-Baixo)) apresentam autocorrelação espacial positiva, estas regiões formam clusters de valores similares. Por outro lado, o segundo e o quarto quadrantes (BA (Baixo-Alto) e AB (Alto-Baixo)) apresentam autocorrelação espacial negativa, ou seja, estas regiões formam clusters com valores diferentes. O diagrama de dispersão de Moran mostra no eixo horizontal a variável de interesse e no vertical, a defasagem espacial (lag) dessa variável (Anselin, 1996).

Os resultados apresentados no diagrama de dispersão de Moran podem ser mapeados, constituindo o denominado mapa de dispersão de Moran, porém, assim como acontece com o diagrama, o mapa apresenta grupos de autocorrelação espacial tanto estatisticamente significativos quanto não significativos. Portanto, as estatísticas de autocorrelação global não têm a capacidade de identificar a ocorrência de autocorrelação local, estatisticamente significante (Almeida, 2012).

Em virtude disso, são utilizados os indicadores de autocorrelação local que examinam os padrões de associação espacial em maiores detalhes. Conforme Anselin (1995), um Indicador Local de Associação Espacial (Local Indicator of Spatial Association - LISA), baseado no $I$ de Moran, pode ser especificado como

$$
I_{i, t}=\frac{\left(y_{i, t}-\mu_{t}\right)^{2}}{m_{0}} \sum_{j}\left(y_{i, t}-\mu_{t}\right)^{2} \text { sendo } m_{0}=\frac{\left(y_{i, t}-\mu_{t}\right)^{2}}{N}
$$


em que $y_{i, t}$ é a observação da variável de interesse na microrregião $i$ para o ano $t, \mu_{t}$ é a média das observações entre as microrregiões para o ano $t$ para a qual o somatório em relação à $j$ é tal que somente os valores vizinhos de $j$ são inclusos.

A estatística pode ser interpretada como: valores positivos significam que há clusters espaciais com valores similares (alto ou baixo); valores negativos significam que há clusters espaciais com valores diferentes entre as regiões e seus vizinhos. Considerando-se que é grande o número das informações computadas, o ideal é mapeá-las, formando-se o denominado mapa de clusters da variável sob análise (Maranduba Junior, 2007).

\section{III.2. Regressão ponderada geograficamente (RPG)}

O modelo RPG é um desenvolvimento do modelo clássico de regressão linear (MCRL) para dados espaciais em corte transversal. Ao contrário dos modelos globais, permite que exista a estimação de coeficientes locais, ou seja, consiste em uma técnica espacial que aborda os efeitos locais das regiões (Brunsdon et al., 1998).

O modelo RPG gera uma regressão local, resultado para cada observação $i$. Nessa regressão, as unidades são ponderadas espacialmente, produzindo estimativas específicas do local. A chave para a atenuação da função de distância é o parâmetro de largura de banda $\alpha$ que define a distância sobre a qual uma única microrregião é afetada por outras unidades territoriais. O parâmetro ideal é aquele que leva a um mínimo valor do critério de informação de Akaike (AIC) (Fotheringham et al., 2003). A estabilidade dos parâmetros sobre os locais é examinada pelo teste de variabilidade geográfica (Li \& Zhu, 2017). O mapeamento dos resultados do RPG fornece informações espaciais tanto sobre a magnitude como a significância das estimativas dos parâmetros (Gezici et al., 2017).

Cada observação é ponderada de acordo com estar mais perto ou mais longe da localização $i$, e esses pesos variam conforme o ponto da regressão se altera. Um relacionamento variado sobre o espaço será tratado por meio do cálculo de uma matriz de peso em que os pesos são calculados para cada ponto $i$. Assim, os dados próximos aos pontos serão mais ponderados e terão mais influência, comparados aos dados mais distantes (Fotheringham et al., 2002).

O conceito geral por trás do modelo de regressão geograficamente ponderada está em consonância com a Lei Tobler (1970), pois admite que os dados mais 
próximos do ponto da regressão têm probabilidade maior de influenciá-lo. Como resultado dessa abordagem, pontos de dados e pontos de regressão funcionam com base em uma matriz de ponderação (Gezici et al., 2017; Almeida, 2012).

A principal vantagem desse modelo é a estimação de um modelo específico para cada região, controlando, portanto, a heterogeneidade espacial extrema. Por meio dessa metodologia, é possível se analisar a existência do processo de convergência para cada área mínima comparável (AMC), ou seja, é possível se especificar o coeficiente beta, a velocidade de convergência e a meia-vida específicos para cada AMC. Ademais, essa metodologia permite o controle da dependência espacial (nas formas de defasagem espacial, de erro e de transbordamentos da variável explicativa) (Ribeiro \& Almeida, 2012).

O RPG, uma técnica de modelagem de regressão local, traz uma nova perspectiva aos modelos de regressão espacial. Este modelo é amplamente separado dos globais, uma vez que pode representar a forma local de análise espacial e pode ser útil para se identificar problemas não estacionários que podem comprometer a inferência extraída de modelos globais.

III.3. Especificações e base de dados

Para analisar o crescimento da agroindústria brasileira em sentido amplo no período de 2006 a $2016^{3}$ considerando as 558 microrregiões, utiliza-se o seguinte modelo:

$$
\begin{aligned}
& \operatorname{CRES}_{E S T_{A I}=}=\alpha_{z}+\beta_{1} Q L_{A I}+\beta_{2} Q L_{A G R O}+\beta_{3} E S T A I_{06}+\beta_{4} S A L_{A I}+\beta_{5} P I B_{P C} \\
&+\beta_{6} E N S . M E D_{E M P_{T}}+\beta_{7} E N S . F U D_{E M P_{T}}+\beta_{8} \text { VALORAD } D_{A G R O}
\end{aligned}
$$

2 De acordo com Favro (2019), as subclasses da CNAE (versão 2.0) que fazem parte do conceito de agroindústria são: todas as subclasses pertencentes à indústria de alimentos, bebidas e fumo. Fabricação de produtos têxteis: 1311-1/00; 1312-0/00; 1321-9/00 e 1322-7/00. Confecção de artigos do vestuário e acessórios: 1412-6/02 e 1414-2/00; Preparação de couros e fabricação de artefatos de couro: 1510-6/00; 1529-7/00; 1531-9/01; Fabricação de produtos de madeira: 1610-2/01, 16102/02, 1621-8/00, 1622-6/01, 1622-6/02, 1622-6/99, 1623-4/00, 1629-3/02, 1629-3/01; Fabricação de celulose, papel e produtos de papel: $1710-9 / 00,1721-4 / 00,1722-2 / 00,1731-1 / 00,1732-0 / 00,1733-$ 8/00, 1741-9/01, 1741-9/02, 1742-7/99; Fabricação de coque, de produtos derivados do petróleo e de biocombustíveis: 1931-4/00 e 1932-2/00; Fabricação de móveis: 3101-2/00.

3 Este recorte temporal foi definido em virtude dos dados utilizados neste estudo serem classificados levando em consideração a CNAE 2.0, onde a disponibilidade da série de dados se dá a partir de 2006. 
A variável dependente (CRES), consiste na taxa de crescimento dos estabelecimentos da agroindústria de 2006 a 2016. São incorporados a esta medida de crescimento, novos estabelecimentos, bem como fechamentos de estabelecimentos existentes. A utilização desta, está em consonância com os estudos de Goetz (1997), Xu (2011) e Yonggang (2013).

Vale destacar que, no caso brasileiro, os estabelecimentos da agroindústria são compostos em sua grande parte por micro e pequenas empresas pelo critério de número de funcionários. De acordo com os dados da Rais (2020), em 2006, 82\% ${ }^{4}$ dos estabelecimentos da agroindústria eram microempresas, $13 \%$ eram empresas de pequeno porte e $3 \%$ eram estabelecimentos de médio porte. Já em 2016, $84 \%$ dos estabelecimentos eram considerados microempresas, $12 \%$ eram empresas de pequeno porte e 3\% eram empresas de médio porte. Tanto em 2006 quanto em 2016, as empresas de grande porte possuíam uma representação pouco expressiva no total de estabelecimentos da agroindústria, chegando a aproximadamente $1 \%$.

As variáveis independentes utilizadas no modelo incluem os fatores determinantes do crescimento do número de estabelecimentos da agroindústria, que são categorizadas em seis grupos: recursos humanos, mercado, custo, infraestrutura, aglomeração e oferta de matéria-prima para o ano de 2006. Os dados para as variáveis explicativas são selecionados no ano inicial do período analisado para o qual a mudança no número de estabelecimentos é medida com base no pressuposto de que esses dados representam os atributos de localização das empresas no tempo que teriam sido tomadas as decisões sobre se abrir, fechar ou manter o estabelecimento.

A variável $Q L_{A I}$, o quociente locacional, representa os fatores de aglomeração da agroindústria. Para o cálculo do $Q L_{A I}$, utiliza-se a seguinte fórmula:

$$
Q L_{A I}=\left(\frac{E_{j}^{i}}{E_{j}}\right) /\left(\frac{E_{B R}^{i}}{E_{B R}}\right)
$$

4 Para a classificação de porte dos estabelecimentos da agroindústria, foi utilizado o conceito do Departamento Intersindical de Estatística e Estudos Socioeconômicos - DIEESE e do Serviço Brasileiro de Apoio às Micro e Pequenas Empresas - Sebrae (2017). As empresas podem ser classificadas como microempresas, pequenas, médias e grandes empresas de acordo com o setor e o número de funcionários. No caso da indústria, onde os segmentos que pertencem à agroindústria estão inseridos, as microempresas são definidas como aquelas com até 19 funcionários, pequenas empresas são definidas como aquelas com 20 até 99 funcionários, as médias são aquelas que possuem de 100 a 499 funcionários e as grandes empresas são aquelas com número de funcionários superior a 500. 
A variável $Q L_{A G R O}$ representa os fatores de aglomeração da agropecuária para capturar a especialização da produção. Seu emprego visa examinar se um alto grau de especialização na agropecuária em determinada localidade cria as condições necessárias para a expansão das empresas existentes ou se contribui para atração de novas empresas. A utilização dessa variável está de acordo com Takano et al. (2018).

A variável $E S T A I_{06}$ consiste no número de estabelecimentos da agroindústria em relação ao total de estabelecimentos existentes na microrregião, no período inicial da análise (ano de 2006). Essa variável é utilizada para medir a aglomeração da indústria devido à alta correlação entre o número de estabelecimentos e o nível de investimento. Essa medida foi usada nos estudos de Davis \& Schluter (2005) e Pruitt \& Tilley (2008).

A variável $S A L_{A R}$ refere-se ao custo da mão de obra, por meio da renda média - medida em número de salários mínimos. Esta variável está de acordo com o trabalho de Gotardo (2016).

A variável $P I B_{P C}$ consiste no PIB per capita e foi utilizada para captar os efeitos de mercado. $\mathrm{O} P I B_{P C}$ reflete o potencial de demanda de uma região e proporciona uma estimativa do tamanho de mercado para os tomadores de decisão. Esta variável está em consonância com Basile et al. (2008), Gotardo (2016) e Silva (2016).

As variáveis $E N S . M E D_{E M P_{T}}$ e $E N S . F U D_{E M P_{T}}$ representam os percentuais de trabalhadores na indústria de transformação que possuem ensino médio e ensino fundamental. Essas variáveis consistem em proxies que retratam o grau de escolaridade da mão de obra.

A variável VALORAD $D_{A G R O}$ consiste na participação do valor adicionado da produção agropecuária em relação ao valor adicionado das demais atividades econômicas ${ }^{5}$. Esta variável foi utilizada no modelo para representar a oferta de insumos para a produção agroindustrial. A utilização dessa variável está em conformidade com MacDonald et al. (2000), Davis \& Schluter (2005) e Pintor (2016). A variável $A R E A_{M I C}$ consiste na área da microrregião. Representa uma proxy para recursos naturais das microrregiões e é utilizada no modelo para mensurar os efeitos da disponibilidade de terra na decisão de localização. A disponibilidade

5 Utilizou-se o valor adicionado porque de acordo com Lopes e Vasconcelos (2008), o Valor Bruto da Produção (VBP) pode apresentar o problema de dupla contagem. Sendo assim, o valor adicionado é mais adequado do que o VBP. 
de terra está, por hipótese, relacionada positivamente com a decisão de seleção do local. Isso se justifica, pois as empresas buscam se localizar onde existe terra disponível para projetos atuais e para futuras expansões. De acordo com Gàlvez $\&$ Webber (2017), o acesso a recursos naturais, especialmente a terra, consiste em um fator importante para a localização da agroindústria. A utilização dessa variável também está em conformidade com Papke (1991), Woodward (1992), Henderson e McNamara (1997), Daltro Barreto et al. (2003), Lambert \& McNamara (2009), Wu (2017), Takano et al. (2018) e Gomes et al. (2019).

A variável DIS representa o custo de transporte, ou seja, mensura a proximidade e o acesso aos mercados consumidores. Vários autores (Von Thünen (1826), Weber (1929), Hoover (1948), Greenhurt \& Greenhurt, (1975), entre outros) destacam a importância dos custos de transporte e afirmam que a indústria se localiza onde esses custos são minimizados, pois quanto menor o custo de transporte, maiores serão as vantagens locacionais que a indústria terá em se instalar nessas localidades. Para a construção dessa variável, utilizou-se o mesmo procedimento realizado por Gotardo (2016), onde se levam em conta as distâncias rodoviárias de cada mercado. Considerando como mercado as capitais estaduais, mensurou-se a distância rodoviária de cada microrregião com sua respectiva capital estadual. Após calculadas as distâncias rodoviárias, realizou-se uma ponderação dessas distâncias com o objetivo de se corrigir vieses de mensuração. Para o cálculo da proxy da distância, utilizou-se a fórmula

$$
D I S=\frac{\text { PIBcapitalestadual }}{\text { PIBnacional }} * \text { distancia }_{i j}
$$

em que $i$ são as microrregiões e $j$ são as capitais dos estados brasileiros. Portanto, distancia $_{i j}$ é a distância rodoviária mensurada em quilômetros da microrregião $i$ para a capital estadual $j$. A utilização desta variável está em consonância com os trabalhos de Henderson \& McNamara (2000), Carod (2005), Barretes; Fiestas \& Hopkins (2015) e Gotardo (2016).

Com relação aos dados utilizados no modelo, verifica-se que o número de estabelecimentos da agroindústria, o salário, as informações sobre emprego industrial e escolaridade (anos de estudos) foram coletados na base de dados da Relação Anual de Informações Sociais (RAIS), publicada pelo Ministério do Trabalho e Emprego (MTE). As informações sobre o Produto Interno Bruto (PIB) e área foram extraídas da base de dados do Instituto de Pesquisa Econômica Aplicada (IPEADATA) e o valor adicionado da produção foi extraído do Instituto Brasileiro de Geografia e Estatística (IBGE). 


\section{RESULTADOS}

IV.1. Distribuição espacial do crescimento dos estabelecimentos da agroindústria no Brasil

A Figura 1 apresenta a distribuição geográfica da taxa de crescimento dos estabelecimentos da agroindústria. As microrregiões em cor mais escura são aquelas com as maiores taxas de crescimento no número de estabelecimentos da agroindústria. Já aquelas denotadas em cor mais clara são as que apresentaram as menores taxas de crescimento. No mapa é possível verificar que grande parte das microrregiões que apresentaram os maiores percentuais de crescimento dos estabelecimentos da agroindústria entre 2006 e 2016 está localizada no Norte, Nordeste e centro-Oeste. Já as microrregiões que apresentaram as menores taxas de crescimento dos estabelecimentos da agroindústria estão concentradas nas regiões Sul, Sudeste e Norte. Essa observação sugere a existência de clusters espaciais.

Figura 1. Distribuição geográfica da taxa de crescimento dos estabelecimentos da agroindústria 2006-2016

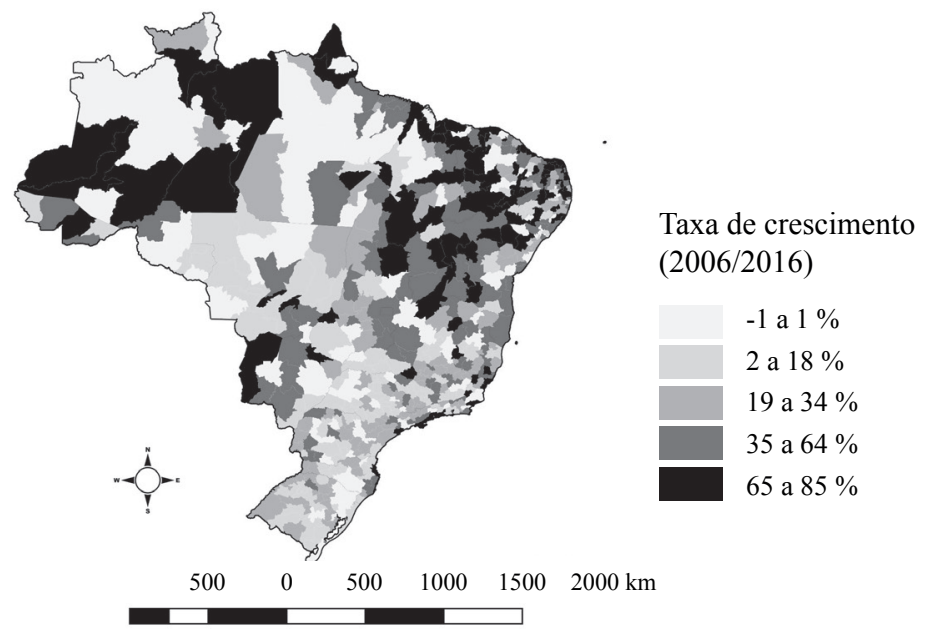

Fonte: elaboração própria a partir do software GeoDa. 
Para se verificar a presença de associação espacial, aplica-se a técnica de Análise Exploratória de Dados Espaciais (AEDE), com a utilização do $I$ de Moran Global e Local Indicator of Spatial Association (LISA).

Na Tabela 2 são apresentados os resultados do índice $I$ de Moran, considerando-se as matrizes, torre, rainha e $k$ vizinhos mais próximos. Verifica-se que todos os valores do $I$ de Moran são positivos e estatisticamente significativos a 1\%, revelando similaridade entre os valores e a localização espacial das microrregiões. Nesse caso, é possível afirmar que as microrregiões com elevada taxa de crescimento dos estabelecimentos da agroindústria estão rodeadas por microrregiões que também possuem elevada taxa de crescimento, ao passo que microrregiões com baixos valores tendem a estar rodeadas por vizinhos que também apresentam baixos níveis de crescimento dos estabelecimentos da agroindústria.

Tabela 2. Coeficiente do I de Moran para a variável taxa de crescimento dos estabelecimentos da agroindústria

\begin{tabular}{lccc}
\hline Convenção & $I$ de Moran & p-valor & z-valor \\
\hline Rainha & 0.15 & 0.00 & 5.83 \\
\hline Torre & 0.15 & 0.00 & 5.77 \\
5 vizinhos mais próximos & 0.15 & 0.00 & 6.40 \\
\hline 7 vizinhos mais próximos & 0.12 & 0.00 & 6.19 \\
\hline
\end{tabular}

Fonte: elaboração própria.

Nota: a pseudossignificância empírica baseada em 999 permutações aleatórias.

A estatística $I$ de Moran mostra indícios da presença de dependência espacial, porém uma complementação da análise necessita ser realizada. Para tanto, utilizou-se a estatística LISA. Os indicadores LISA podem ser visualizados pelo mapa de clusters (Figura 2). Este mapa apresenta informações sobre o tipo de autocorrelação espacial que existe entre as localidades que apresentaram indicadores LISA significativos. Por esse mapa podem-se identificar as informações de clusters espaciais em quatro categorias de observações: AA (Alto-Alto), BB (Baixo-Baixo), AB (Alto-Baixo) e BA (Baixo-Alto). 
Figura 2. Mapa de clusters LISA para a variável taxa de crescimento dos estabelecimentos da agroindústria 2006-2016

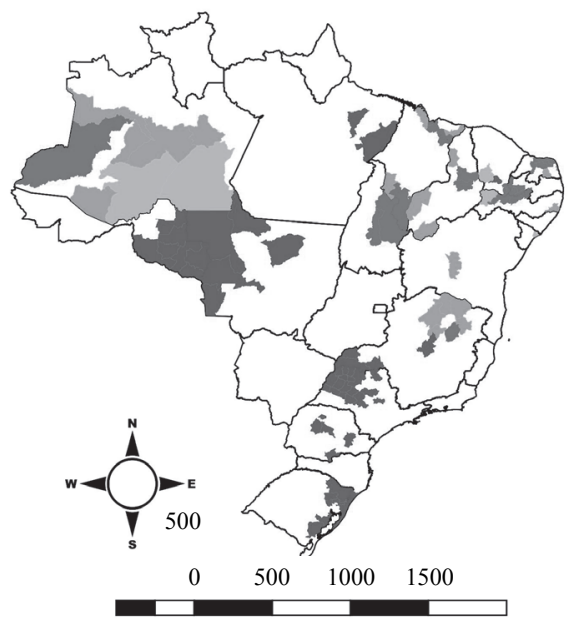

LISA CLUSTER - CRES_EST_AI

Não significativo

Alto - Alto (AA)

Baixo - Baixo (BB)

Baixo - Alto (BA)

Alto-Baixo (AB)

Nota: Mapa com 999 permutações e nível de significância de 5\%. Obs.: Mapa de clusters LISA com base na matriz de contiguidade cinco vizinhos mais próximos ${ }^{6}$.

Fonte: elaboração própria a partir do software GeoDa.

Na Figura 2, pode-se observar que os agrupamentos Alto-Alto (AA), Alto-Baixo (AB) e Baixo-Alto (BA), para a taxa de crescimento dos estabelecimentos da agroindústria, estão presentes nas regiões Norte, Nordeste e Sudeste. Especificamente, os clusters AA indicam as microrregiões que apresentaram taxa de crescimento dos estabelecimentos da agroindústria acima da média e cujas cinco microrregiões vizinhas mais próximas estão circundadas por microrregiões que também apresentaram crescimento acima da média. Estes agrupamentos estão concentrados nos estados do Amazonas, Ceará, Pernambuco, Piauí, Rio Grande do Norte, Tocantins, Maranhão e Minas Gerais.

No que concerne aos clusters Baixo-Baixo (BB), verifica-se que estes estão concentrados nos estados do Rio Grande do Sul, Paraná, São Paulo, Minas Gerais, Mato Grosso e Pará e representam as microrregiões com baixo crescimento dos esta-

6 A matriz 5 vizinhos foi utilizada por apresentar o maior valor do $I$ de Moran. A matriz de contiguidade $\boldsymbol{k}$ mais próxima indica que cada município está conectado ao mesmo número $\boldsymbol{k}$ de vizinhos, é utilizada para se determinar a conectividade espacial entre unidades de análise. 
belecimentos da agroindústria, que são circundadas por microrregiões que também apresentam baixo crescimento no número de estabelecimentos da agroindústria.

\section{IV.2. Regressão ponderada geograficamente}

Visando-se analisar os possíveis casos de heterogeneidade extrema das microrregiões, estimou-se o modelo RPG. Ao se comparar os critérios de ajustamento, o $\mathrm{R}^{27}$ e o Critério de Informação de Akaike ${ }^{8}$ (AIC) dos modelos global e local (Tabela 3), encontrou-se um valor menor do AIC e maior do $\mathrm{R}^{2}$ para o modelo local, em comparação ao global. Esse resultado sugere que a estimação de um modelo que considera a existência de múltiplos equilíbrios é mais ajustada à análise dos condicionantes do crescimento dos estabelecimentos da agroindústria.

\section{Tabela 3. Diagnóstico da regressão do modelo RPG}

\begin{tabular}{lccc}
\hline Modelo & Regressão & AIC & $\mathrm{R}^{2}$ \\
\hline \multirow{2}{*}{ RPG } & Global & 1279.37 & 0.17 \\
& Local & 1214.33 & 0.34 \\
\hline
\end{tabular}

Fonte: Elaboração própria.

$\mathrm{Na}$ Tabela 4 são apresentados os resultados das regressões locais do modelo RPG e o teste de diferença de critérios, cujo objetivo é identificar quais variáveis apresentam coeficientes com variabilidade geográfica. Os valores negativos e menores que 2 indicam que os coeficientes das variáveis não têm linearidade espacial. Neste estudo as variáveis cujos coeficientes têm variabilidade geográfica são $E S T A I_{06}, V A L O R A D_{A G R O}, A R E A_{M I C}, E N S . M E D_{E M P_{T}}, P I B_{P C}, Q L_{A G R O}$. Isso significa que as respostas dessas variáveis devem ser analisadas localmente, pois elas diferem em cada ponto da regressão, ou seja, a resposta a determinado estímulo não é constante, apresentando impactos diferentes ao longo do território.

$7 \quad \mathrm{R}^{2}$ conhecido como coeficiente de determinação, é o indicador mais utilizado para medir a qualidade do ajustamento de uma linha de regressão. Ele mede a proporção ou percentual da variação de Y explicada pelo modelo de regressão (Gujarati \& Porter, 2011).

8 O critério de informação de Akaike (AIC) impõe uma medida corretiva mais dura que $\mathrm{R}^{2}$. Ao comparar dois ou mais modelos, o modelo com valor mais baixo do AIC é preferido (Gujarati \& Porter, 2011). 
Tabela 4. Estatística dos coeficientes locais

\begin{tabular}{lccccc}
\hline Variáveis & Mínimo & Máximo & Mediana & STD & $\begin{array}{c}\text { Diferença de } \\
\text { critério }\end{array}$ \\
\hline CONSTANT & 00.11 & 00.71 & 00.31 & 00.16 & -1.29 \\
\hline$E S T A I_{06}$ & -0.74 & -0.08 & -0.22 & 0.14 & -9.88 \\
\hline VALORAD & -0.16 & 0.18 & -0.02 & 0.10 & -2.45 \\
\hline$A R E A_{M I C}$ & -0.22 & 0.24 & -0.02 & 0.10 & -5.19 \\
\hline$E N S . F U N D_{E M P_{T}}$ & -0.03 & 0.16 & 0.06 & 0.05 & 1.50 \\
\hline$E N S . M E D_{E M P_{T}}$ & -0.28 & 0.40 & -0.03 & 0.11 & -25.14 \\
\hline$S A L_{A I}$ & -0.24 & -0.00 & -0.03 & 0.04 & 2.73 \\
\hline$Q L_{A I}$ & -0.16 & 0.11 & -0.04 & 0.04 & 2.61 \\
\hline$Q L_{A G R O}$ & -0.08 & 0.20 & -0.02 & 0.08 & -5.25 \\
\hline$P I B_{P C}$ & -0.35 & 0.46 & -0.00 & 0.17 & -11.28 \\
\hline$D I S$ & -0.37 & -0.01 & -0.03 & 0.14 & -0.84 \\
\hline
\end{tabular}

Fonte: elaboração própria a partir do software GWR4.

IV.3. Mapeamento dos coeficientes do modelo RPG

Após a verificação das variáveis que apresentam variabilidade geográfica no modelo proposto, apresenta-se o mapeamento dos coeficientes locais para cada variável. De acordo com Fotheringham et al. (2000), esse tipo de análise mostra não só a variação de um fenômeno, como também a localização dessa variação.

A Figura 3 mostra os resultados da variável $P I B_{P C}$; verifica-se que a mesma apresentou efeito local positivo em microrregiões dos estados do Ceará, Maranhão, Paraíba, Pernambuco, Piauí e Rio Grande do Norte. Essa variável reflete o poder de compra de cada microrregião, portanto, quanto maior o PIB per capita, maior será o número de estabelecimentos industriais instalados em determinada microrregião. 
Esse fato ocorre nas microrregiões do Nordeste, pois, além de esta região apresentar crescimento econômico significativo no período de 2002 a $2005^{9}$, também exibiu queda das assimetrias sociais. Esse novo quadro econômico com taxas positivas, os investimentos privados e a elevação de consumo dos segmentos de renda mais baixa têm sido fatores de repercussão midiática do Nordeste nos últimos anos. Sendo assim, elevação da renda dos segmentos mais pobres, aceleração do consumo e redução das desigualdades sociais contribuem para o aumento do consumo de produtos agroindustriais (Carvalho, 2008).

Figura 3. Distribuição dos coeficientes locais da variável $P I B_{P C}$

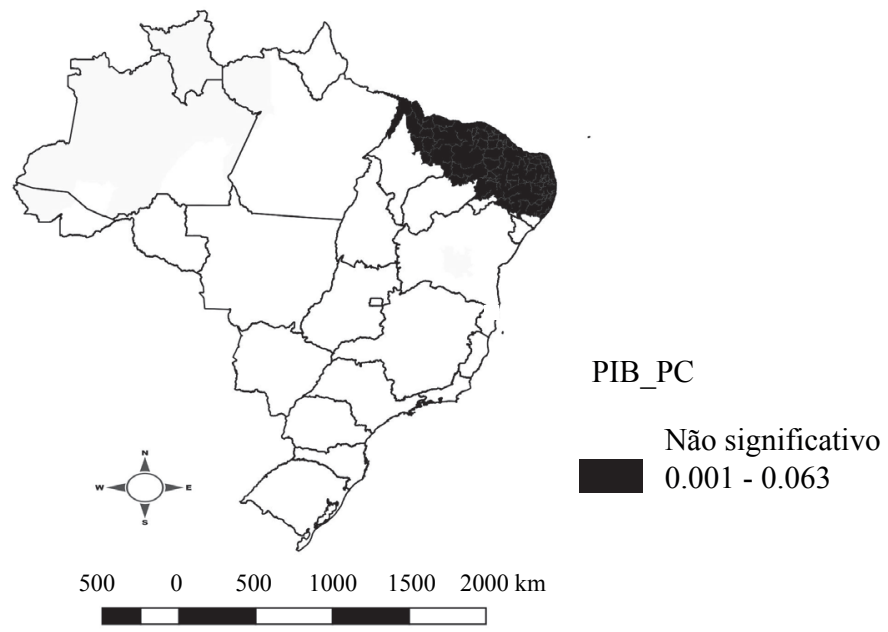

Nota: Coeficientes estatisticamente significativos a $5 \%$.

Fonte: elaboração própria.

Uma justificativa para esse resultado pode ser encontrada em Schmit \& Bills (2007), onde os autores sinalizam que o incremento da renda dos consumidores aumentará a demanda por produtos alimentícios de valor agregado, representando uma possível fonte de crescimento dos fabricantes de alimentos e bebidas.

9 Esse fato ocorre na região Nordeste em virtude de apresentar, no período de 2002 a 2015, uma expansão de suas atividades superior àquela observada na economia brasileira. O PIB regional cresceu a uma média anual de 3.3\%, enquanto o País obteve taxas médias de 2.9\% (IBGE, 2017). 
No que concerne aos resultados dos coeficientes da variável valor adicionado da agropecuária $V A L O R A D_{A G R O}$ (Figura 4), a mesma apresentou impacto positivo sobre a taxa de crescimento dos estabelecimentos da agroindústria, ou seja, quanto maior o valor adicionado da agropecuária, maior tende a ser o crescimento dos estabelecimentos da agroindústria. Pode-se observar que essa variável apresentou efeito local positivo nas microrregiões concentradas nos Estados de Mato Grosso, Rondônia e na região Nordeste nos Estados de Alagoas, Ceará, Maranhão, Paraíba, Pernambuco, Piauí, Rio Grande do Norte. Nesta região, o efeito locacional do valor da produção agropecuária se dá nessas microrregiões, em virtude de a aglomeração industrial estar localizada na faixa oriental litorânea (Carvalho, 2008). Nessas microrregiões, destaca-se a produção de frutas e hortaliças, que consiste em atividade econômica dinâmica e estratégica para o desenvolvimento sustentável do interior dos estados nordestinos. As potencialidades do Nordeste para a produção de alimentos provenientes de frutas, legumes e hortaliças estão apoiadas em um conjunto de variáveis, como clima, cultura, conhecimento técnico e condições econômicas que resultaram em vantagens comparativas e competitivas, e na concentração de grandes áreas consolidadas na produção dessas espécies de vegetais. Além do mais, algumas dessas áreas de concentração possuem melhores condições de escoamento da produção e são dotadas de infraestrutura básica, onde se encontram instaladas a maioria das agroindústrias nordestinas (BNB, 2008).

Figura 4. Distribuição dos coeficientes locais da variável $V A L O R A D_{A G R O}$

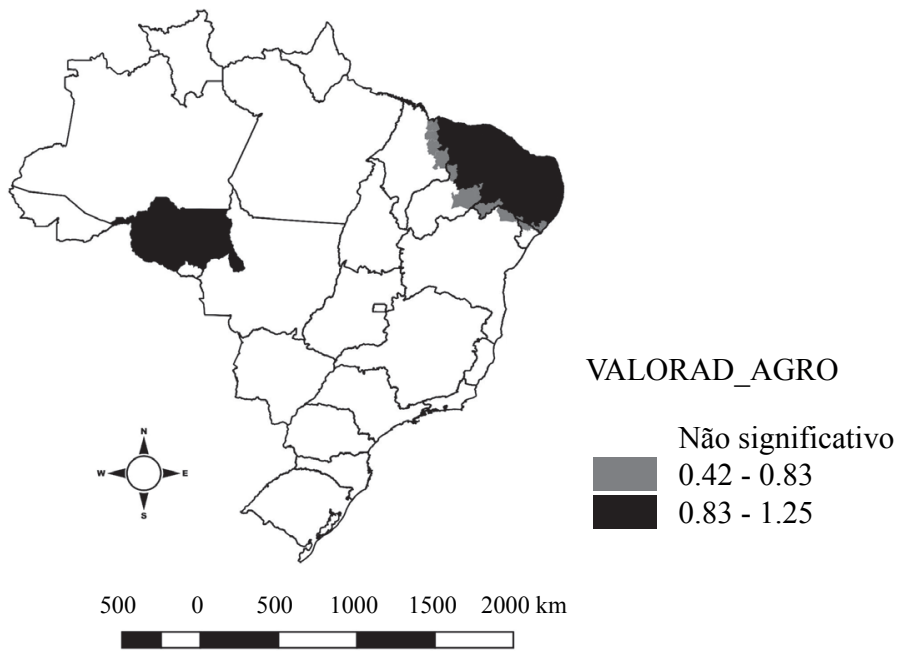

Nota: coeficientes estatisticamente significativos a $5 \%$.

Fonte: elaboração própria. 
Em Rondônia, observa-se que a maior parte das microrregiões apresentou efeito local desta variável. Rondônia é um estado onde a produção agropecuária tem importância do ponto de vista socioeconômico. Em 2015, o setor foi responsável por $11.9 \%$ do PIB estadual, bem acima da média nacional, que foi de $6.4 \%$, em valores correntes. Bovinos, soja, leite e café são os principais produtos agropecuários produzidos no estado (IBGE, 2017; CEPEA, 2015). A produção agropecuária deste estado contribui para o desenvolvimento da agroindústria, visto que, segundo a RAIS (2018), em Rondônia, dos estabelecimentos da indústria de transformação existentes no ano de 2015 , aproximadamente $45 \%$ fazem parte da agroindústria.

No que concerne ao estado do Mato Grosso, a microrregião que apresentou impacto local foi a de Aripuanã, pertencente à região Noroeste do estado. De acordo com o Instituto Mato-Grossense de Economia Agropecuária (2017), a principal atividade econômica da região é a pecuária. A estrutura produtiva desta microrregião corrobora para o desenvolvimento da agroindústria, fato que pode ser evidenciado ao considerar os dados da RAIS (2018), que apontam que essa microrregião apresenta participação representativa de estabelecimentos agroindustriais em relação à indústria de transformação. Em 2015, esse segmento produtivo representou aproximadamente $73 \%$ dos estabelecimentos industriais dessa região.

Mediante o exposto, pode-se verificar que as microrregiões que apresentaram efeito local positivo obtiveram elevada produção agropecuária e possuem representativa participação da agroindústria em sua estrutura produtiva industrial. Esses fatos reforçam a importância de a agroindústria estar próxima às fontes de insumos.

Com relação aos resultados do quociente locacional da agropecuária $\left(Q L_{A G R O}\right)$, conforme exposto na Figura 5, verifica-se que esta variável apresentou efeito local positivo em todas as microrregiões do estado do Espírito Santo e parte das microrregiões dos estados de Minas Gerais, Rio e Janeiro, Bahia e Goiás. Esse resultado reforça que a presença da especialização na produção agropecuária (medida por meio do emprego formal neste setor) pode contribuir para o crescimento da agroindústria.

Essa evidência está explícita nos dados do Censo Agropecuário (2006), que mostra Minas Gerais como o estado com maior número de estabelecimentos agropecuários e com o maior número de empregados em estabelecimentos agrícolas. Para Castro (2014), uma possível explicação para o grande número de empregados neste setor consiste na grande presença, neste estado, de lavouras permanentes com uso intensivo de mão de obra, como é o caso do café. Tanto o número de estabele- 
cimentos quanto os de empregos na agropecuária contribuem para que esta região seja especializada neste setor.

Figura 5. Distribuição dos coeficientes locais da variável $Q L_{A G R O}$

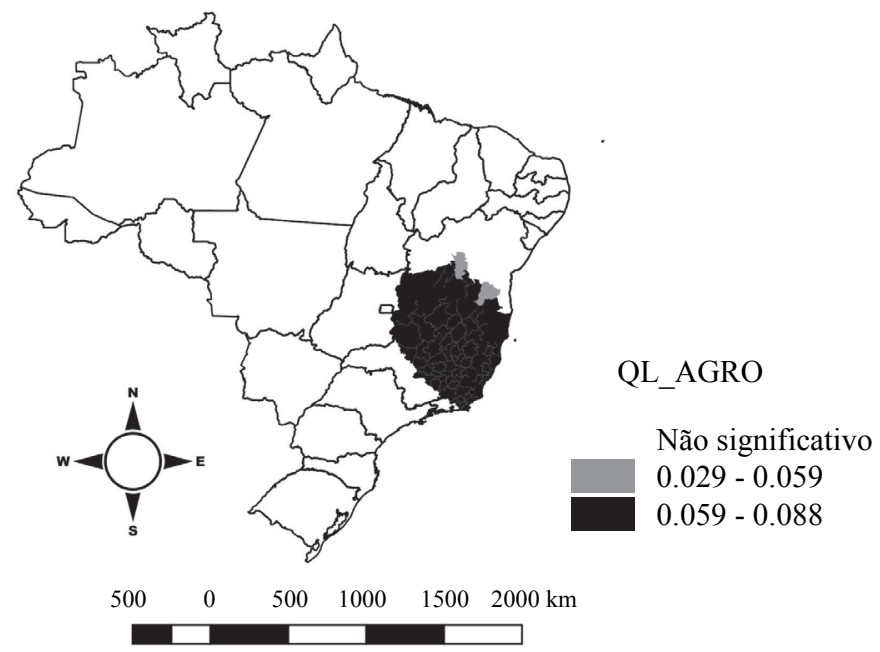

Nota: coeficientes estatisticamente significativos a 5\%.

Fonte: elaboração própria.

$\mathrm{Na}$ Bahia, o efeito local do quociente locacional da agropecuária $\left(Q L_{A G R O}\right)$ está presente na região oeste, onde se verifica efeito positivo. De acordo com a SEI (2017), o oeste baiano transformou-se, ao longo dos últimos 35 anos, no maior polo produtor de grãos do estado, em grande parte, direcionados para a exportação, fato que comprova a especialização na produção agropecuária nessa região.

No Espírito Santo, verifica-se efeito local desta variável em todas as microrregiões. Nesse estado, que é formado por municípios que possuem dimensão territorial inferior à média dos municípios brasileiros, destacam-se atividades agropecuárias intensivas no uso de mão de obra como a produção de café arábica, a pecuária leiteira, a cana-de-açúcar, a olericultura, o fomento florestal e a fruticultura, que geram renda em pequenas áreas, sendo o agronegócio a principal atividade econômica em 82\% dos municípios capixabas (Governo do estado do Espírito Santo, 2008; IBGE, 2010). 
Já no estado do Rio de Janeiro, o efeito local positivo do quociente locacional da agropecuária $\left(Q L_{A G R O}\right)$, se deu nas microrregiões das regiões noroeste, norte e centro fluminense. Uma das justificativas para esses resultados consiste no fato destas regiões serem consideradas importantes produtoras de produtos agropecuários. Por meio dos dados do Censo Agropecuário de 2006, verificou-se que, no estado do Rio de Janeiro, as regiões norte (representada pelas microrregiões de Campos dos Goytacazes e Macaé), noroeste (representada pelas microrregiões de Itaperuna e Santo Antônio de Pádua) e centro fluminense (representada pelas microrregiões de Três Rios, Cantagalo-Cordeiro, Nova Friburgo e Santa Maria Madalena) possuem uma participação de $24 \%, 15 \%$ e $19 \%$ respectivamente do valor da produção agropecuária do estado. Vale destacar que, de acordo com esses dados, a região norte fluminense é a região que possui a maior participação em termos de valor da produção agropecuária do estado do Rio de Janeiro.

Na região norte, a produção agropecuária é realizada por unidades de maior porte, especialmente as ligadas ao setor sucroalcooleiro, já a região Noroeste se destaca como importante centro agrícola regional, com atividades de pecuária leiteira, fruticultura e hortaliças (Silva, 2009).

No que diz respeito à variável área da microrregião (AREA_MIC) (Figura 6), verificou-se impacto positivo, indicando que quanto maior a área da microrregião, maior tende a ser o crescimento dos estabelecimentos da agroindústria nas microrregiões dos estados do Amazonas, Acre, Rondônia, Roraima e parte das microrregiões dos estados do Pará e do Mato Grosso. Uma justificativa para esse resultado consiste no fato de tanto a região Norte como a região Centro-Oeste do país disporem de maiores quantidades de terras, o que pode contribuir para a expansão do parque industrial, e por estas regiões terem avançado, ao longo dos últimos anos, na expansão da fronteira agrícola de produção, principalmente nos estados de Rondônia, Pará. A fronteira agrícola de produção caracteriza-se por ser uma área potencial de uso, devendo concentrar três elementos fundamentais: a existência de mercados relacionados a produtos ligados à terra e ao trabalho, a disponibilidade de território para exploração e a presença de um sistema de transportes (Mueller, 1992). No que concerne às microrregiões que apresentaram impacto positivo para a variável AREA_MIC, é importante verificar as características das atividades econômicas predominantes em cada região de impacto. Conforme Costa (2008) e Costa \& Fernandes (2016), por ordem de importância, as mesorregiões sudeste paraense (PA), a leste rondoniense (RO) e a centro amazonense (AM) são as que mais têm contribuído para o desenvolvimento da agropecuária na região Norte. 
A mesorregião sudeste paraense tem se constituído como o principal e mais complexo sistema agrário da região, em que predominam atividades patronais relacionadas à pecuária de corte. A concentração de grandes projetos financiados pela Superintendência de Desenvolvimento da Amazônia (SUDAM), a partir de meados da década de 1960, explicando a predominância dessa atividade no contexto regional (COSTA, 2008; COSTA; FERNANDES, 2016). O leste rondoniense, segundo sistema agrário mais importante, conforme Costa (2008) e Costa \& Fernandes (2016), tem no produtor camponês seu principal agente rural, o qual se vincula à pecuária leiteira e culturas permanentes.

Já com relação à região centro amazonense, verifica-se a predominância de pequenos produtores, tendo como atividade principal os sistemas agroflorestais. Este setor apresentou participação de $35 \%$ do VBP da região, seguido pela pecuária leiteira e de culturas permanente (33\%) e pela pecuária de corte (23\%) (Costa, 2008).

As microrregiões do Mato Grosso que apresentaram efeito local estão localizadas nas regiões noroeste, norte, oeste e médio norte. De acordo com o IMEA (2018), nas regiões norte e noroeste, a predominância é a produção pecuária, já na região do médio norte, a principal atividade é a produção de grãos.

Figura 6. Distribuição dos coeficientes locais da variável AREA_MIC
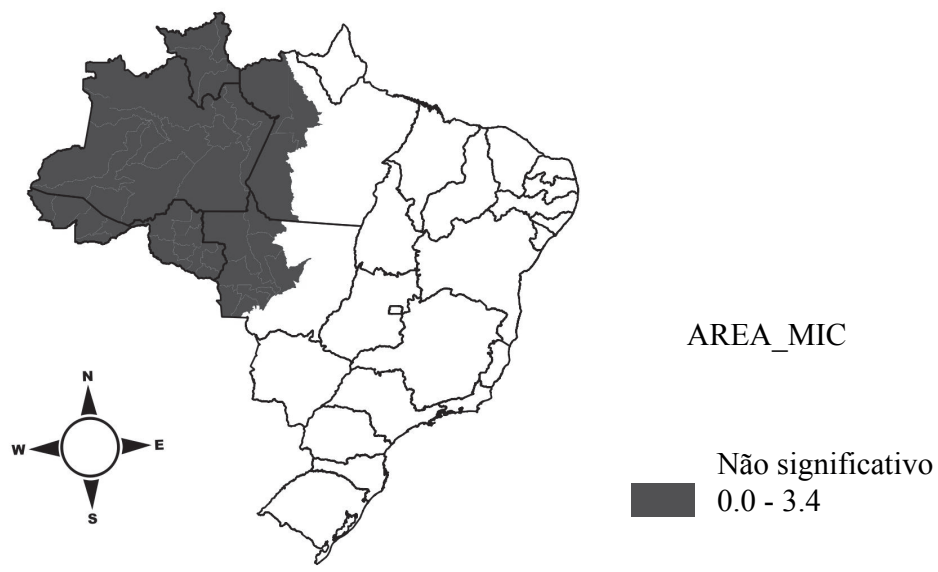

$$
\begin{array}{llllll}
500 & 0 & 500 & 1000 & 1500 & 2000 \\
\hline
\end{array}
$$

Nota: coeficientes estatisticamente significativos a $5 \%$

Fonte: elaboração própria. 
Sendo assim, ao se analisar as características das regiões de impacto, pode-se constatar que as regiões onde predomina a produção agropecuária são aquelas que apresentam potencial para a expansão da agroindústria.

Entende-se, portanto, que a expansão da produção da agropecuária contribui para o desenvolvimento do setor industrial. Para Johnston \& Mellor (1961), o desenvolvimento econômico é caracterizado por um aumento substancial da demanda por produtos agrícolas. Sendo assim, a agricultura pode realizar uma contribuição líquida para o capital, para investimento fixo e para o crescimento da indústria, pois o aumento do rendimento líquido da agricultura pode ser importante estímulo à expansão industrial. Essa justificativa é confirmada por Bacha (2012), que afirma que a agricultura tem o papel de gerar matérias-primas necessárias ao desenvolvimento industrial nacional. Essa explicação do autor serve de base, inclusive, para a determinação da localização espacial de boa parte das indústrias nacionais.

A variável ESTAI_06 (Figura 7), apresentou sinal negativo com maior impacto nas microrregiões do estado da Bahia, especificamente aquelas localizadas nas regiões oeste, sul, centro sul e vale do São Francisco. Esse fato sugere a presença de deseconomias de aglomeração associadas à localização da agroindústria.

Figura 7. Distribuição dos coeficientes locais da variável ESTAI_06

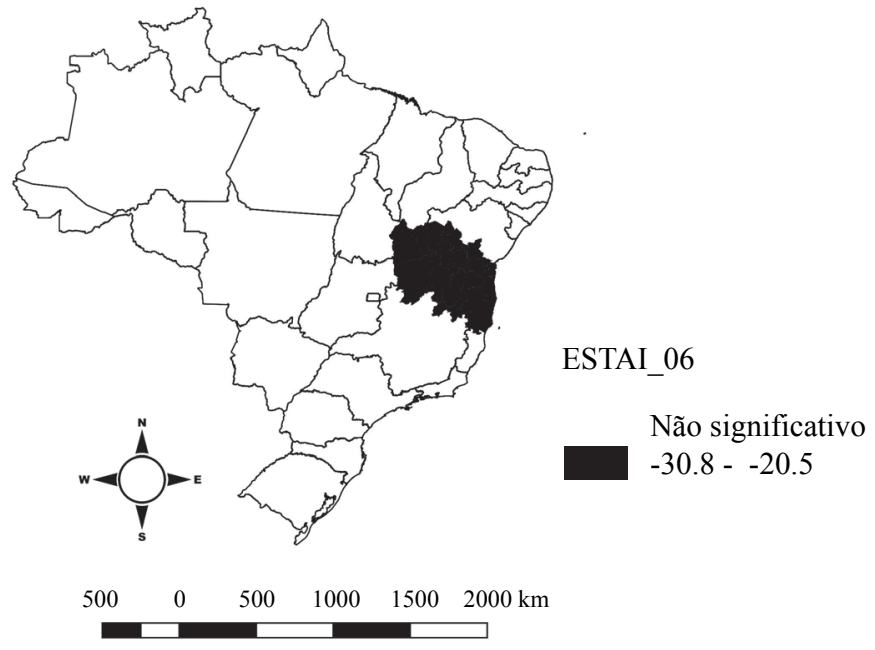

Nota: coeficientes estatisticamente significativos a $5 \%$

Fonte: elaboração própria. 
Os resultados dos coeficientes locais referentes à variável percentual de trabalhadores com ensino médio (ENS.MED.EMPT) podem ser verificados por meio da Figura 8, onde se constata que esta variável apresentou efeito local positivo na região Norte, indicando uma relação direta, ou seja, quanto maior o percentual de funcionários com ensino médio, maior é o crescimento dos estabelecimentos da agroindústria. Este fato se justifica em virtude da importância da agroindústria em termos de empregos formais nesta região. De acordo com os dados da RAIS (2018), em 2016, aproximadamente 43\% dos empregos formais da indústria de transformação desta região pertenceram à agroindústria. Quando se analisa em nível de estados, em 2016, no Acre, Roraima e Rondônia, este segmento produtivo representou $66 \%, 69 \%$ e $70 \%$ do emprego referente à indústria de transformação.

Figura 8. Distribuição dos coeficientes locais da variável ENS.MED.EMPT

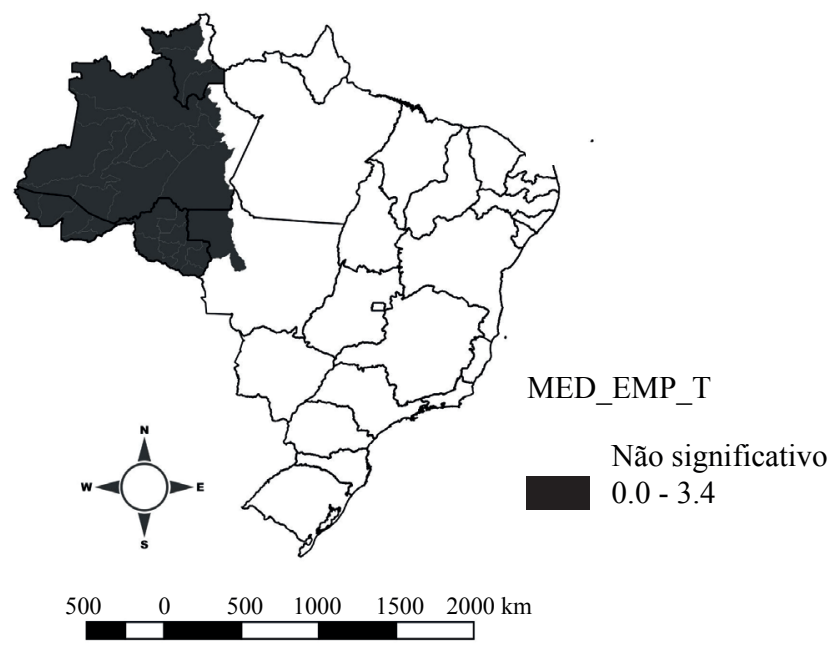

Nota: coeficientes estatisticamente significativos a $5 \%$.

Fonte: elaboração própria.

Por meio dos resultados, podem-se verificar os efeitos locais com predominância nas regiões Norte e Nordeste. Nestas regiões constatam-se, nos últimos anos, modificações que a abertura agrícola ocasionou na configuração regional, principalmente quanto ao setor industrial, contribuindo, assim, para o crescimento da produção agroindustrial (Pintor, 2016). 
Dado o exposto, pode-se concluir que os resultados do modelo apresentado têm importantes implicações para formulação de políticas voltadas para o desenvolvimento da agroindústria que devem ser implantadas atentando-se para as questões regionais, pois uma política desenhada para uma determinada região pode não ser conveniente para ser aplicada em outra, visto que poderá produzir resultados diferentes.

\section{CONCLUSÕES}

Este estudo teve por objetivo analisar o crescimento da agroindústria no Brasil no período de 2006 a 2016. Para tanto foram empregadas as técnicas econométricas de Análise Exploratória de Dados Espaciais (AEDE) e Regressão Ponderada Geograficamente (RPG).

A AEDE indicou a existência de autocorrelação espacial positiva na taxa de crescimento dos estabelecimentos da agroindústria, evidenciando clusters alto-alto nas regiões Norte e Nordeste e clusters baixo-baixo nas regiões Sul, Sudeste e Centro-Oeste.

No modelo RPG, verificou-se que os efeitos locais das microrregiões que foram estatisticamente significativas concentraram-se nas regiões Norte e Nordeste do país, onde se constatou impacto relevante da produção e especialização das microrregiões na agropecuária. Outro aspecto importante verificado no estudo consiste no fato de que o crescimento da agropecuária brasileira nas regiões Norte, Nordeste e Centro-Oeste, no período em estudo, foi importante para a consolidação da agroindústria nestas regiões. Com essa técnica, foi possível identificar as regiões onde as variáveis têm impactos geograficamente mais fortes.

Os resultados do estudo confirmam que o crescimento da agroindústria é influenciado pelos aspectos locacionais existentes em cada região. Esses fatores podem contribuir para que regiões, valendo-se das vantagens locacionais e das heterogeneidades regionais, possam desenvolver agroindústrias competitivas e, assim, corroborar a geração de emprego e renda, e cooperar para o crescimento da demanda por produtos agropecuários.

A principal contribuição deste estudo é avançar na compreensão sobre a agroindústria em sentido amplo e conhecer os determinantes locacionais que influenciam seu crescimento em nível microrregional, haja vista que estudos sobre este segmento da indústria ainda é pouco explorado na literatura. A consideração da heterogeneidade espacial consiste em outra contribuição, pois a maior parte dos 
trabalhos nessa área não considera os efeitos espaciais em processos de localização da firma, porém, como a agroindústria possui forte correlação com os aspectos locacionais, optou-se por se analisar o modelo considerando-se esses aspectos. Por fim, outra contribuição deste estudo foi realizar uma análise que verificasse o impacto local das variáveis por meio do modelo RPG.

Diante do exposto, pode-se constatar que este estudo não contribui apenas para se identificar os determinantes da localização da agroindústria, mas também para futuras análises espaciais do setor industrial e da agropecuária ao utilizar o método RPG. Esta técnica, ao captar os efeitos locais, fornece instrumentos mais efetivos para a elaboração de políticas públicas em relação aos modelos globais, por avaliar o impacto de cada variável de forma local.

\section{REFERÊNCIA}

Almeida, E. S. (2012). Econometria Espacial Aplicada. (1a ed.). Campinas, SP: Alínea. Anselin, L. (1995). Local indicators of spatial association - LISA. Geographical Analysis, 27(2), 93-115.

Anselin, L. (1996). The Moran scatterplot as an ESDA tool to assess local instability in spatial association. In: Fischer, M., Scholten, H., \& Unwin, D. Spatial Analytical Perspectives on GIS in Environmental and Socio-Economic Sciences. Londres: Taylor and Francis.

Banco do Nordeste do Brasil [BNB] (2008). A agroindústria de alimentos de frutas e hortaliças no Nordeste e demais áreas de atuação do BNB Desempenho Recente e Possibilidades de Políticas. (Série Documentos do Etene No. 24). Fortaleza.

Barrantes, R., Fiestas, J., \& Hopkins, Á., (2015). Patrones de localización de las empresas agroindustriales en el Perú. Lima: IEP. (Serie documentos de trabajo, Documento No.157). Chile.

Basile, R., Castellani, D., \& Zanfei, A., (2008). Location choices of multinational firms in Europe: The role of EU cohesion policy. Journal of International Economics, 74(2), 328-340.

Carod, J. M. A. (2005). Determinants of industrial location: an application for Catalan municipalities. Papers in Regional Science, 84(1), 105-120.

Carvalho, C. P. O. (2008). Nordeste: sinais de um novo padrão de crescimento. In: XXXVI Encontro Nacional de Economia - ANPEC, 2008. Anais, Salvador.

Castro, C. N. (2014). A agropecuária na região Sudeste: limitações e desafios futuros. (Texto para Discussão No.1952). Ipea, Brasília.

Centro de Estudos Avançados em Economia Aplicada [CEPEA], (2015). PIB do agronegócio brasileiro. Obtido em 02/01/2018 em https://www.cepea.esalq.usp.br. 
Daltro Barreto, F. A., Castelar, I., \& Benevides, A. D. A. (2003). Integração comercial, dotação de fatores e desigualdade de renda pessoal dos estados brasileiros. Pesquisa e Planejamento Econômico, 33(3), 597-624.

Davis, D. E., \& Schluter, G. E. (2005). Labor-force heterogeneity as a source of agglomeration economics and empirical analysis of county-level determinants of food plant entry. Journal of Agricultural and Resource Economics, 30(3), 480-501.

Fotheringham, A. S. Brunsdon, C., \& Charlton, M. (2000). Quantitative geography: perspectives on spatial data analysis. Sage publications, Edição: First, Londres.

Gàlvez, N. E., \& Webber, M. (2017). Territorial tools for agro-industry development. Food and Agriculture Organization of the United Nations (FAO). Rome, Italy: FAO.

Gezici, F., Walsh, B. Y., \& Kacar, S. M. (2017). Regional and structural analysis of the manufacturing industry in Turkey. The Annals of Regional Science, 59(1), 209-230.

Granco, G., Sant'Anna, A. C., Bergtold, J. S., \& Caldas, M. M. (2018). Factors influencing ethanol mill location in a new sugarcane producing region in Brazil. Biomass and Bioenergy, 111, 125-133. doi:10.1016/j. biombioe.2018.02.001

Goetz, S., (1997). State-and county-level determinants of food manufacturing establishment growth: 1987-1993. American Journal of Agricultural Economics, 79(3), 838-850.

Gomes, C. E., Lemos Lima, R., Fraga, G. J., \& Parré, J. L. (2019). Comércio internacional e PIB per capita: uma análise utilizando a abordagem espacial. Revista de Economia, 40(71), 1-27.

Gotardo, D. M., (2016). Determinantes da localização industrial: uma análise para as mesorregiões brasileiras. Dissertação (mestrado) - Programa de Pós Graduação em Economia, Universidade Estadual do Oeste do Paraná UNIOESTE, Campus Toledo.

Governo do Espírito Santo (2018). Diversificação de culturas amplia o crescimento do agronegócio no Espírito Santo. Obtido em 02/09/2018 em https://www. es.gov.br.

Henderson, J. R., \& McNamara, K. T. (1997). Community attributes influencing local food processing growth in the U.S. Corn Belt. Canadian Journal of Agricultural Economics, 45, 235-250.

Hoover, E. M. (1948). The location of economic activity. New York: McGraw-Hill. Huang, Y., \& Leung, Y. (2002). Analysing regional industrialisation in Jiangsu province using geographically weighted regression. Journal of Geographical Systems, 4(2), 233-249. 
Instituto brasileiro de geografia e estatística [IBGE]. (2017). Contas Regionais 2002-2015. Rio de Janeiro. Obtido em 29/04/2020 em https://ibge.gov.br. Instituto brasileiro de geografia e estatística [IBGE]. (2006). Censo Agropecuário. Rio de Janeiro. Obtido em 29/04/2020 em https://sidra.ibge.gov.br/pesquisa/ censo-agropecuario/censo-agropecuario-2006/segunda-apuracao.

Instituto mato-grossense de economia agropecuária [IMEA] (2017). Mapa das Macrorregiões do IMEA. Obtido em 05/04/2018 em http://www.imea.com.br. Johnston, B. F., \& Mellor, J. W. (1962). El Papel de la Agricultura en el Desarrollo Económico. El trimestre Económico, 29(2), 279-307.

Lambert, D. M., MC Namara, K. T., \& Garrett, M. I. (2006). An application of spatial Poisson models to manufacturing investment location analysis. Journal of Agricultural and Applied Economics, 38(1), 105-121.

Lambert, D. M., \& McNamara K. T., (2009). Location Determinants of Food Manufacturers in the U.S., 2000-2004: Are Nonmetropolitan Counties Competitive? Agricultural Economics, 40(6), 617-630.

Li, Y. C., \& Zhu, K., (2017). Spatial Dependence and Heterogeneity in the Location Processes of New High-tech Firms in Nanjing, China. Papers in Regional Science, 96(3), 519-535.

Liu, Z. (2013). Geographical Concentration of Manufacturing Industries in China-Measurements and Determinants. Dissertation (Doctor of Philosophy), University of Connecticut.

Lopes, L. M., \& Vasconcellos, M. A. S. (2008). Manual de Macroeconomia: Nível Básico e Nível Intermediário (3a ed.). São Paulo: Editora Altas.

Monteiro, F. D. S. C., \& Lima, J. P. R., (2017). Desindustrialização regional no Brasil. Nova Economia, 27(2), 247-293.

Monteiro Neto, A., \& Silva, R. O. (2018). Desconcentração territorial e reestruturação regressiva da indústria no Brasil: padrões e ritmos. (Texto para discussão No. 2402). IPEA, Brasília.

Partridge, M. D., Rickman, D. S., Ali, K., \& Olfert, R. (2008). The geographic diversity of US nonmetropolitan growth dynamics: A geographically weighted regression approach. Land economics, 84(2), 241-266.

Pintor, E., (2016). Determinantes da expansão da fronteira de produção das culturas de arroz, milho e soja no Norte e Nordeste brasileiro. (Dissertação) - PósGraduação em Desen. Regional e Agronegócio, Universidade Estadual do Oeste do Paraná, Toledo. (Dissertação de mestrado).

Polyzos, S., Tsiotas, D., \& Niavis, S. (2015). Analyzing the location decisions of agro-industrial investments in Greece. International Journal of Agricultural and Environmental Information Systems, 6(2), 77-100.

Relação Anual de Informações Sociais [RAIS], (2018). Obtido em 05/04/2018 em http://trabalho.gov.br/rais. 
Sabater, L. A., Tur, A. A., \& Azorín, J. M. N. (2011). Análise Exploratória de Dados Espaciais (AEDE). In: J. S. Costa; T. P. Dentinho \& P. Nijkamp (Org). Compendio de Economia Regional, (Vol. 2, $1^{\text {a }}$ ed., pp. 259-293). Cascais: Princípia.

Santos, G. R. (2013). Agroindústria e desenvolvimento: uma análise da distribuição regional e dos efeitos diretos na economia. Planejamento e Políticas Públicas, Brasília, 2, 363-420.

Santos, G. R. (2014). Agroindústria no Brasil: um olhar sobre indicadores de porte e expansão regional. (Radar No. 31: tecnologia, produção e comércio exterior). Brasília: IPEA.

Silva, R. D. S. (2009). Estrutura industrial e desenvolvimento regional no Estado do Rio de Janeiro (1990-2008). (Tese inédita de doutorado). Programa de Pós-Graduação em Desenvolvimento Econômico, Universidade Estadual de Campinas, Campinas.

Silva, C. A., Baker, D., Shepherd, A. W., Jenane, C., \& Miranda-da-Cruz, S. (2009). Agro-industries for development. Italia: CAB International and FAO. Food and Agriculture Organization of the United Nations

Serviço Brasileiro de Apoio às Micro e Pequenas Empresas [SEBRAE], (2017). Anuário do Trabalho nos Pequenos Negócios 2015. Obtido em 23/04/2018 em http://www.fao.org/3/a-i0157e.pdf

Superintendência de Estudos Econômicos e Sociais da Bahia [SEI] (2018). Cidades do Agronegócio no Oeste Baiano. (Texto para discussão No.13). Salvador. Obtido em 05/04/2018 em http://www.sei.ba.gov.br.

Takano, K., Tsutsumi, M., \& Kikukawa, Y. (2018). Spatial Modeling of Industrial Location Determinants in Japan: Empirical Analysis Using Spatial Econometric Approaches. Review of Urban \& Regional Development Studies, 30(1), 26-43.

$\mathrm{Xu}, \mathrm{Y} .$, \& Warner, M. E. (2015). Understanding employment growth in the recession: the geographic diversity of state rescaling. Cambridge Journal of Regions, Economy and Society, 8(2), 359-377.

Wu, W., (2017). Agglomeration Economy and Input-output Linkage: Evidence from the Entry of the Agro-food Industry in China. Japanese Journal of Agricultural Economics, 19, 48-53. Obtido em https://doi.org/10.18480/ jjae.19.0_48

(C) 2021 por los autores; licencia no exclusiva otorgada a la revista Estudios económicos. Este artículo es de acceso abierto y distribuido bajo los términos y condiciones de una licencia Atribución-No Comercial 4.0 Internacional (CC BY-NC 4.0) de Creative Commons. Para ver una copia de esta licencia, visite http://crea-tivecommons.org/licenses/by-nc/4.0 
